\title{
COMMENTARY
}

\section{Multilevel competing risks in the evaluation of nosocomial infections: time to move on from proportional hazards and even from hazards altogether}

\author{
Alvaro Muñoz ${ }^{1}$, Nicole Mongilardi ${ }^{2}$ and William Checkley ${ }^{2^{*}}$
}

See related research by Wolkewitz et al., http://ccforum.com/content/18/2/R64

\begin{abstract}
A competing risk is an event (for example, death in the ICU) that hinders the occurrence of an event of interest (for example, nosocomial infection in the ICU) and it is a common issue in many critical care studies. Not accounting for a competing event may affect how results related to a primary event of interest are interpreted. In the previous issue of Critical Care, Wolkewitz and colleagues extended traditional models for competing risks to include random effects as a means to quantify heterogeneity among ICUs. Reported results from their analyses based on cause-specific hazards and on sub-hazards of the cumulative incidence function were indicative of lack of proportionality of these hazards over time. Here, we argue that proportionality of hazards can be problematic in competing-risk problems and analyses must consider time by covariate interactions as a default. Moreover, since hazards in competing risks make it difficult to disentangle the effects of frequency and timing of the competing events, their interpretation can be murky. Use of mixtures of flexible and succinct parametric time-to-event models for competing risks permits disentanglement of the frequency and timing at the price of requiring stronger data and a higher number of parameters. We used data from a clinical trial on fluid management strategies for patients with acute respiratory distress syndrome to support our recommendations.
\end{abstract}

\footnotetext{
* Correspondence: wcheckl1@jhmi.edu

2 Division of Pulmonary and Critical Care, School of Medicine, Johns Hopkins University, 1800 Orleans Avenue, Suite 9121, Baltimore, MD 21205, USA Full list of author information is available at the end of the article
}

In the previous issue of Critical Care, Wolkewitz and colleagues [1] analyzed data from a multi-center cohort study of 159 ICUs and 109,202 admissions to better understand how both patient-level and ICU-level characteristics affect nosocomial infections (NIs). NIs are a leading cause of death in the ICU despite being largely preventable [2]. Reductions of up to $70 \%$ have been achieved via infection control strategies for specific NIs [3], but this has not been universal across settings. Thus, it is important to define both high-risk patients and high-risk settings and identify interventions that prevent NIs, for which data analysis methods to determine risk factors for specific events are pertinent. Wolkewitz and colleagues [1] acknowledge the difficulty of the problem caused by heterogeneity across ICUs and the importance of competing risks when analyzing risk factors for NIs and present a statistical approach to handle both of these complexities.

\section{Heterogeneity across intensive care units}

In recent years, increasing attention has been given to the role of ICU organization and processes of care on patient-centered outcomes [4-9]. Some of these previous investigations have also recognized substantial heterogeneity in ICU organization $[4,9]$ that can contribute to variations in rates of mortality of critically ill patients across hospitals and may help explain why some interventions achieve improvements only in specific settings. By using a multilevel approach to analyze patient-level and ICU-level characteristics, Wolkewitz and colleagues thereby avoid loss of valuable information that may help explain differences in clinical outcomes.

\section{Ciomed Central}




\section{Competing risks in critical care}

Competing risks are important in the ICU because a large proportion of patients may be discharged or die before developing the event of interest (for example, NIs). To account for competing risks, Wolkewitz and colleagues [1] extended methods to compare causespecific hazards (CSHs) and sub-hazards (SUBHs) of the cumulative incidence functions between study groups [10] by incorporating random effects to quantify heterogeneity. However, despite wide recognition that proportionality of hazards does not occur in most situations, their results are presented under such an assumption.

Time to move on from proportionality of hazards Proportionality of hazards has additional hurdles in competing risks [11]. In the case of two competing risks, proportionality cannot hold simultaneously for all CSHs and SUBHs [12]. Specifically, at most two of the four (two events and two types of hazards) can be proportional but without restriction of which two [11]. Even in the case in which two of the four hazards are proportional, there is strong tethering between the hazard ratios [11]. In particular, when the CSHs and SUBHs for a given event type simultaneously fulfill proportionality, the two hazard ratios must be equal and this fact holds regardless of the number of competing risks. A consequence of this result is that analyses reporting $\mathrm{CSH}$ and SUBH ratios with different values divulge a lack of proportionality in at least one of the hazard types, as is the case in the analysis by Wolkewitz and colleagues [1] for number of beds, Acute Physiology and Chronic Health Evaluation II score, days in hospital, type of diagnosis and trauma as presented in their Table 2. Fine and Gray [13] anticipated that a lack of proportionality would be common in competing-risk problems. While it is possible to test for a lack of proportionality, power is often

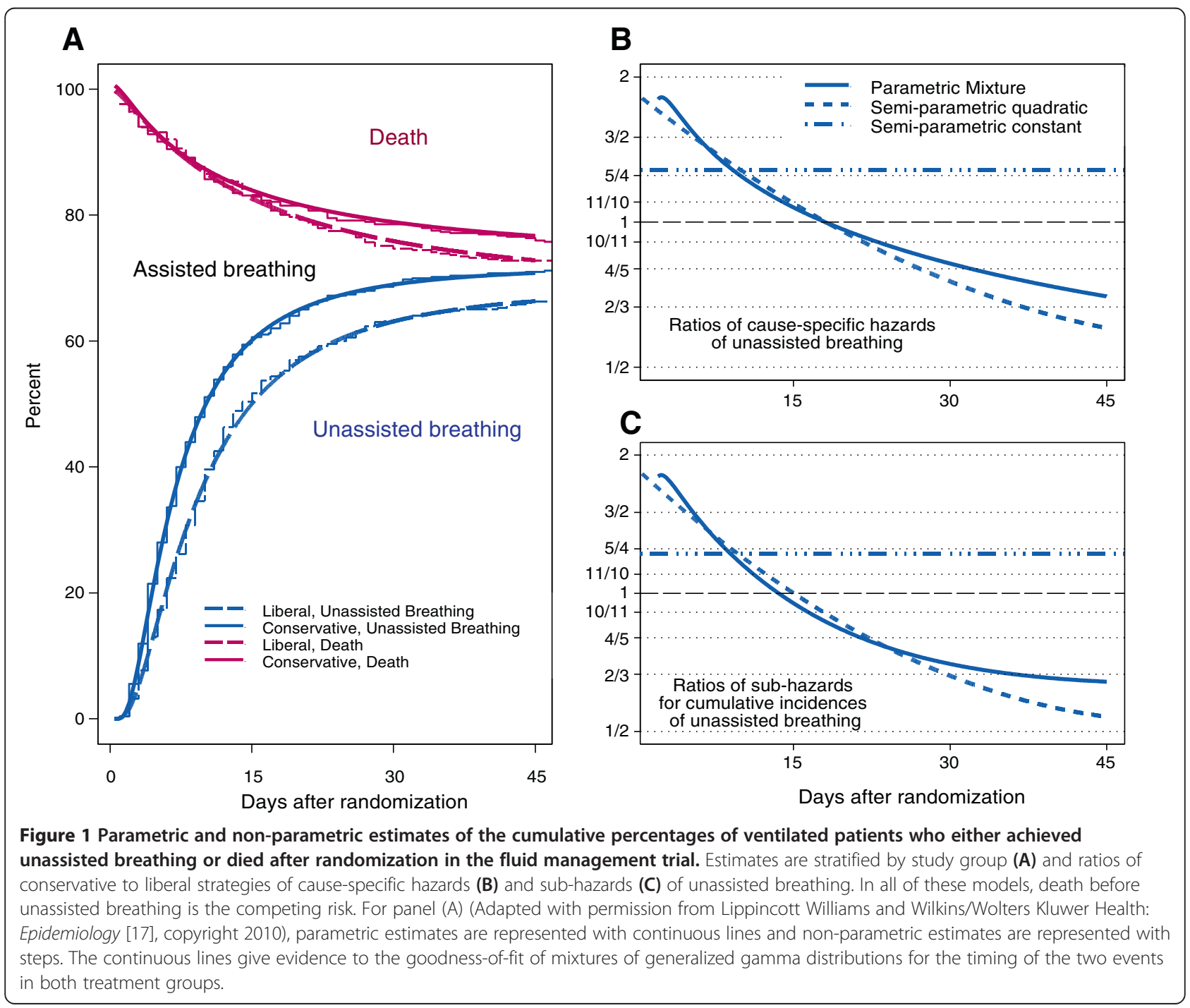


limited in most situations (for example, short follow-up time or heavy censoring). Thus, default analyses should include covariate and time interactions which can be easily calculated and depicted [14].

\section{Even time to move on from hazards altogether}

Hazards as a metric of disease occurrence along with semi-parametric methods have provided a means to understanding many diseases. However, hazards have limitations [15] that become compounded in competing-risk problems: $\mathrm{CSH}$ and SUBHs are decoupled; CSHs lack specificity as they are strongly influenced by the competing event; SUBHs are specific but they are intrinsically tethered because their cumulative incidences must add up to one; both CSHs and SUBHs combine frequency and timing of events, making it difficult to identify exposures that modify only the timing of an event but not the frequency.

Approaching the analysis of competing risks as a mixture of flexible and succinct parametric distributions overcomes limitations of hazards and can provide enlightening insights $[16,17]$. To illustrate this, in Figure 1A we show the cumulative incidences among individuals receiving mechanical ventilation of achieving unassisted breathing and of dying in the hospital at different days after being randomly assigned to receive either a liberal or conservative fluid management strategy [17]. The core inference from this analysis was the beneficial effect of conservative fluid management by significantly reducing the days to achieve unassisted breathing but having no effect on the overall frequency of unassisted breathing and on timing of death [17]. This is a very specific finding. In contrast, Figures $1 \mathrm{~B}$ and $1 \mathrm{C}$ present the inappropriate and oversimplistic summary provided by the analyses under proportional-hazards assumptions (horizontal lines with dashes and dots) and the agreement of a strong downward trend of the hazard ratios from the mixture of parametric distributions (solid curves) and the semi-parametric analysis permitting treatment and time interactions (short-dashed curves). The inference from both analyses and from the two hazard types would be that conservative fluid management increases the hazards of unassisted breathing in the first 2 weeks but precludes unassisted breathing among those who remained mechanically ventilated for longer. Although these inferences are not incorrect, they are murky. Mixture models enable the disentanglement of frequency and timing in competing risks. However, they require strong data and may demand large numbers of parameters. The data in Wolkewitz and colleagues are 'as strong as they get', and it remains of interest to explore new approaches beyond the novel inclusion of random effects that the authors have put forward.
Abbreviations

CSH: Cause-specific hazard; NI: Nosocomial infection; SUBH: Sub-hazard.

Competing interests

The authors declare that they have no competing interests.

Authors' contributions

AM, NM, and WC reviewed and approved the final version of the commentary. All authors read and approved the final manuscript.

\section{Acknowledgments}

AM was supported by the National Institutes of National Diabetes and Digestive and Kidney Diseases (UO1-DK-66116). WC was supported by a K99/R00 Pathway to Independence Award (R00HL096955) from the National Heart, Lung and Blood Institute, National Institutes of Health. The authors thank ARDS Network Investigators for use of the Fluid and Catheter Treatment Trial data.

\section{Author details}

${ }^{1}$ Department of Epidemiology, Bloomberg School of Public Health, Johns Hopkins University, 615 N Wolfe St, Suite E7648, Baltimore, MD 21205, USA. ${ }^{2}$ Division of Pulmonary and Critical Care, School of Medicine, Johns Hopkins University, 1800 Orleans Avenue, Suite 9121, Baltimore, MD 21205, USA.

\section{Published: 27 May 2014}

\section{References}

1. Wolkewitz M, Cooper BS, Palomar-Martinez M, Alvarez-Lerma F, OlaecheaAstigarraga P, Barnett AG, Harbarth S, Schumacher M: Multilevel competing risk models to evaluate the risk of nosocomial infection. Crit Care 2014, 18:R64.

2. Klevens RM, Edwards JR, Richards CL Jr, Horan TC, Gaynes RP, Pollock DA, Cardo DM: Estimating health care-associated infections and deaths in US hospitals, 2002. Public Health Rep 2007, 122:160-166.

3. Harbarth S, Sax H, Gastmeier P: The preventable proportion of nosocomial infections: an overview of published reports. J Hosp Infect 2003, 54:258-266.

4. Checkley W, Martin GS, Brown SM, Chang SY, Dabbagh O, Fremont RD, Girard TD, Rice TW, Howell MD, Johnson SB, O'Brien J, Park PK, Pastores SM, Patil NT, Pietropaoli AP, Putman M, Rotello L, Siner J, Sajid S, Murphy DJ, Sevransky JE, United States Critical IIIness and Injury Trials Group Critical IIIness Outcomes Study Investigators: Structure, process, and annual ICU mortality across 69 centers: United States critical illness and injury trials group critical illness outcomes study. Crit Care Med 2014, 42:344-356.

5. Wilcox ME, Chong CA, Niven DJ, Rubenfeld GD, Rowan KM, Wunsch $\mathrm{H}_{\text {, }}$ Fan E: Do intensivist staffing patterns influence hospital mortality following ICU admission? A systematic review and meta-analyses. Crit Care Med 2013, 41:2253-2274

6. Wallace DJ, Angus DC, Barnato AE, Kramer AA, Kahn JM: Nighttime intensivist staffing and mortality among critically ill patients. N Engl J Med 2012, 366:2093-2101.

7. Treggiari MM, Martin DP, Yanez ND, Caldwell E, Hudson LD, Rubenfeld GD: Effect of intensive care unit organizational model and structure on outcomes in patients with acute lung injury. Am J Respir Crit Care Med 2007, 176:685-690.

8. Vincent JL, Rello J, Marshall J, Silva E, Anzueto A, Martin CD, Moreno R, Lipman J, Gomersall C, Sakr Y, Reinhart K, EPIC II Group of Investigators: International study of the prevalence and outcomes of infection in intensive care units. JAMA 2009, 302:2323-2329.

9. Vincent JL, Marshall JC, Namendys-Silva SA, François B, Martin-Loeches I, Lipman J, Reinhart K, Antonelli M, Pickkers P, Njimi H, Jimenez E, Sakr Y, On behalf of the ICON investigators: Assessment of the worldwide burden of critical illness: the intensive care over Nations (ICON) audit. Lancet Respir Med 2014, 2:38-386.

10. Andersen PK, Geskus RB, de Witte T, Putter H: Competing risks in epidemiology: possibilities and pitfalls. Int J Epidemiol 2012, 41:861-870.

11. Muñoz A, Abraham AG, Matheson M, Wada N: Non-proportionality of hazards in the competing risks framework. In Risk Assessment and Evaluation of Predictions. Edited by Lee MLT, Gail M, Pfeiffer R, Satten G, Cai T, Gandy A. New York: Springer; 2013:3-22. 
12. Latouche A, Allignol A, Beyersmann J, Labopin M, Fine JP: A competing risks analysis should report results on all cause-specific hazards and cumulative incidence functions. J Clin Epidemiol 2013, 66:648-653.

13. Fine J, Gray RJ: A proportional hazards model for the subdistribution of a competing risk. J Am Stat Assoc 1999, 94:496-509.

14. Antiretroviral Therapy Cohort Collaboration (ART-CC): Influence of geographical origin and ethnicity on mortality in patients on antiretroviral therapy in Canada, Europe, and the United States. Clin Infect Dis 2013, 56:1800-1809.

15. Hernán MA: The hazards of hazard ratios. Epidemiology 2010, 21:13-15.

16. Cox C, Chu H, Schneider MF, Muñoz A: Parametric survival analysis and taxonomy of hazard functions for the generalized gamma distribution. Statist Med 2007, 26:4352-4374.

17. Checkley W, Brower RG, Muñoz A, NIH Acute Respiratory Distress Syndrome Network Investigators: Inference for mutually exclusive competing events through a mixture of generalized gamma distributions. Epidemiology 2010, 21:557-565.

$10.1186 /$ cc13892

Cite this article as: Muñoz et al:: Multilevel competing risks in the evaluation of nosocomial infections: time to move on from proportional hazards and even from hazards altogether. Critical Care 2014, 18:146 